\title{
Controlling and the Use of UAVs as Important Components of Smart Logistical Operations
}

\author{
Martin Holubčík ${ }^{1 *}$ and Jakub Soviar ${ }^{1}$ \\ ${ }^{1}$ University of Žilina, Department of Management Theories, Faculty of Management Science and \\ Informatics, Žilina, Slovakia; Email:martin.holubcik@fri.uniza.sk, jakub.soviar@fri.uniza.sk
}

\section{*Corresponding Author: Martin Holubčík}

Received: 15 May 2021; Revised: 30 May 2021; Accepted: 20 October 2021; Published: 19

November 2021

Abstract: Modern controlling is an interdisciplinary field that allows management to manage properly, thereby creating the basis for good decision-making. Logistics operations in smart companies need to be not only properly set up, but also properly controlled and improved. The purpose of the article is to analyze the controlling environment in a selected company and point out possible improvements in logistics activities and devices, with a view to preventing different types of problems. For this purpose, observations of the internal logistics processes in a selected company were used and quantified to assess its internal state. On the basis of the data, controlling measures are put forward to improve the management of the company's logistics activities. The results of the research highlight the opportunities that exist through controlling activities to collect and analyze information about the logistics activities of a company. By doing so, employees can be given greater responsibility for the fulfilment of their tasks and contribute to the streamlining of logistics processes. For managers, the implementation of controlling represents a change in the way of thinking and managing a company.

Keywords: Controlling, logistics operations, smart devices, smart companies

\section{Introduction to Controlling}

Controlling within a company primarily works on the basis of feedback. The information generated from available data sources supports additional or new procedures for the management of a company and their decision-making. Based on the results processed with the help of controlling methods and activities, business decisions are influenced in the near and distant futures [1,2].

Controlling is a set of rules, respectively a subsystem of the management system, which helps to achieve a company's goals, prevent surprises, and "lights up red" in time when danger arises and requires effective management to take action to eliminate it [3]. 
Controlling is a management tool whose function is to coordinate the planning, control and provision of the information base with the aim of improving business results [4].

Controlling is an essential part of every business. Irrespective of company size, legal form or subject of business, controlling in general provides the necessary support for every managerial decision.

Controlling is one of the primary functions of company management, which is focused on achieving set goals. It is a process whereby actual results are compared to a company's assumptions. The aim is to ensure the continuity of data collection concerning the achievement of objectives and the planned individual activities for doing so, and to subsequently propose corrective measures for the company's management to postulate.

The role of a manager is to monitor and evaluate the processes within a company. Controlling is helpful in supporting the implementation of corrective measures to prevent unpredictable situations that can lead a company to unnecessarily generate less profits [5].

In companies, as in medicine, it is necessary to make a diagnosis and suggest treatment options. The management tool for treating operational problems, and therefore the future of a company, is controlling, which connects several management and information subsystems e.g. planning, budgeting, accounting, forecasting, etc.).

As part of ongoing research activities, an analysis was undertaken of the role of financial controlling and the willingness to implement it in several small and medium-sized enterprises operating in the wood and furniture industries in the Slovak Republic. From the data garnered from a survey, it was found that more than $80 \%$ of the analyzed companies have already encountered the concept of controlling, but only two-thirds of them know what controlling means, and therefore know its benefits. The results reveal that despite the many advantages and positive effects of controlling, the use of this modern management tool in small and medium-sized enterprises in the analyzed sectors is limited to subsidiaries of foreign companies or those companies with foreign capital participation [6].

However, it is necessary to point out that the aforementioned benefits and effects of controlling, respectively the individual subsystems thereof, do not take immediate effect when applied in practice. The implementation of controlling represents a big change for a company.

Organisations that use controlling to anticipate risk situations usually implement four basic activities [7]:

1. Identification and documentation of planned or ongoing business processes.

2. Definition of anticipated risks and the controls to limit them.

3. Planning of regular internal audits.

4. Recording the results of ongoing but also actual inspections and their results. 
Controlling as a management support system can reconcile all the information available to it, irrespective of whether this comes from the external or internal environment. For the management of a company, it can help their decision-making by enabling them to check compliance with their plans, analyze deviations and propose corrective measures, so that, for example, a decision is forthcoming with regards to outsourcing applications.

Modern controlling is interdisciplinary. This enables the top managements of companies to correctly set strategic goals on the basis of the real opportunities that exist in a constantly changing economic environment [8-9].

The idea of controlling and collecting data from logistics processes within a company is also supported by Majercak, et al. They state that innovation can only be realized through the early detection of the relevant needs and requirements of consumers. Processes and measures focused on innovation must be implemented in accordance with the phase of a product's life cycle. All these measures together lead to efficacy [10].

Lizbetin et al. reveal how it is possible, based on process monitoring, to shift towards the production and use of plastic pallets in logistics rather than wooden pallets [11].

Under operational analysis, which is applied to solve various economic and technical issues related to inventory management, it is also possible to set up controlling activities [12].

This new point of view has conditioned the emergence of new approaches in business management, including, for example, Business Intelligence (BI) and Competitive Intelligence (CI). $\mathrm{BI}$ is oriented towards the internal environment, while CI is more oriented towards the external environment, in particular towards the behaviour of the competition. In other words, BI works with information that is inside a company and CI works mainly with information that is outside a company. $[13,14]$.

CI is also an interdisciplinary field. It requires appropriate training focused on customer needs, buyer psychology, competitor behaviour, trend research and the changing conditions within society. Because the goal is to create a unique competitive advantage - to differentiate - the profession of CI manager requires education in marketing, business and other skills to master the highest, strategic level of management in business.

Control techniques and statistical analyses are essential tools and determine the efficacy with which a company sets up and improves processes [15].

Airikka, P. points out that advanced control methods are more beneficial and profitable than conventional control methods. Advanced control methods generate cost savings and leads to improved product quality [16].

Obstacles to well-functioning controlling [17-21]: 
- Problems in changing the thinking and habits of employees. People who move around in a business environment are dependent on its success, but are often full of bad habits and personal interests. This can create obstacles to the effective functioning of business discipline and therefore impact significantly on its success.

- A lack of staff able to perform the role of controller and be responsible for the implementation and operation of controlling. This includes people with a variety of privileges, which are often very capable specialists, developers, programmers or sales representatives who, instead of performing to the best of their abilities, have slipped over time into constant reasoning.

- Weaknesses in the detailed and systematic control of total costs. The reason for this lies in the reluctance to adapt accounting structures, in particular the analytical breakdown of accounts and cost centres, which is often based on unreasonable adherence to normal practice.

- Problems associated with changing the organisational structure of a company. This applies to management at all levels. After all, it is mainly managers with the relevant competencies that have the power to delegate work and become more efficient. In reality, the reverse is very often the case, whereby the focus is on the achievement of short-term goals.

- Inappropriate placement of the controller in the organisational structure and the incorrect definition of their competencies

- Poor equipment in terms of computer technology, both hardware and software, for the implementation of controlling.

\section{Use of Controlling to Identify Logistics Problems in a Company}

The problem that is discussed in the following case study is the high level of defective products.

Although the problem was identified by the top management, the responsibility lay with the production and technical departments. With controlling procedures in place, and therefore access to sufficient and appropriate data, the problem could have been resolved much earlier. Unfortunately, this was not the case.

The problem arose during the production process, after the feedstock was mixed, melted and poured into the production lines. According to the employees, the production lines were either obsolete, in need of modernization (specific machine components), or required investment in completely new ones. However, the situation did not exclude problems in the process of mixing (inappropriate ratios; use of poor quality additives). The operators themselves were not viewed as a contributory factor to the problem. Their interventions were minimal during the production process. Their role was to control progress on the production lines, to manually move the products to the next part of the production process, but only after a production phase was finished. 
It was not possible to determine exactly the indicators for the defective products over time without access to the company's internal documents. However, it is our opinion that the problem occurred randomly, making it impossible to determine the exact intervals it manifested itself. In general, the production line would produce defective products throughout the day. The estimate was that every tenth product was defective. However, on occasions, the extent of the problem would result in the production line producing defective products for an entire hour.

Until now, the company's solution has been to ignore the issue and not take any action to resolve it. Instead, it recycles the defective products by putting them back into the production process. Although this reduces the severity of the problem, it is still a waste of resources. After all, the company still bears the costs of producing the (defective) products, with the consequence that there is no return in terms of value added.

The ideal solution is to identify the production line that produces the most defects, and then to invest in a new, more modern production line. This would present an opportunity to streamline raw material management and eliminate the need for overproduction. This is based on the assumption that the new production line applies the latest technologies. As a result, the costs of storage, transport, energy consumption, etc. would decrease, making the return on investment high. The suggestion is to finance the replacement of one production line from the profits in the next accounting period so that it is not necessary to take out a loan and get into debt.

Occurrence rate - high defect rate - every 10th piece.

Costs - the estimated cost of modernizing the production line and adjusting the technological process and the reorganisation of the production hall, based on similar projects in other manufacturing companies, is $€ 200,000-350,000$.

Risk level - high risk - non-optimised processes are causing corporate resources to be wasted, with defects driving up costs, something the company should be focused on minimising.

\section{The Impact of Business Problems on Objectives}

In this section, we propose appropriate controlling activities that will serve to identify problems in a timely manner and solve them.

The key objectives are to:

(a) increase profits for the following financial year by $20 \%$;

(b) reduce the quantity of goods in stock in the following marketing year by $10 \%$;

(c) reduce the amount of overproduction by $10 \%$ when implementing customer orders in the following marketing year.

(d) reduce the daily cost of defects by $10 \%$ in the following marketing year. 
The fulfilment of objectives 2 - 4 will lead to the fulfilment of the first (see schematic diagram below - figure 1).

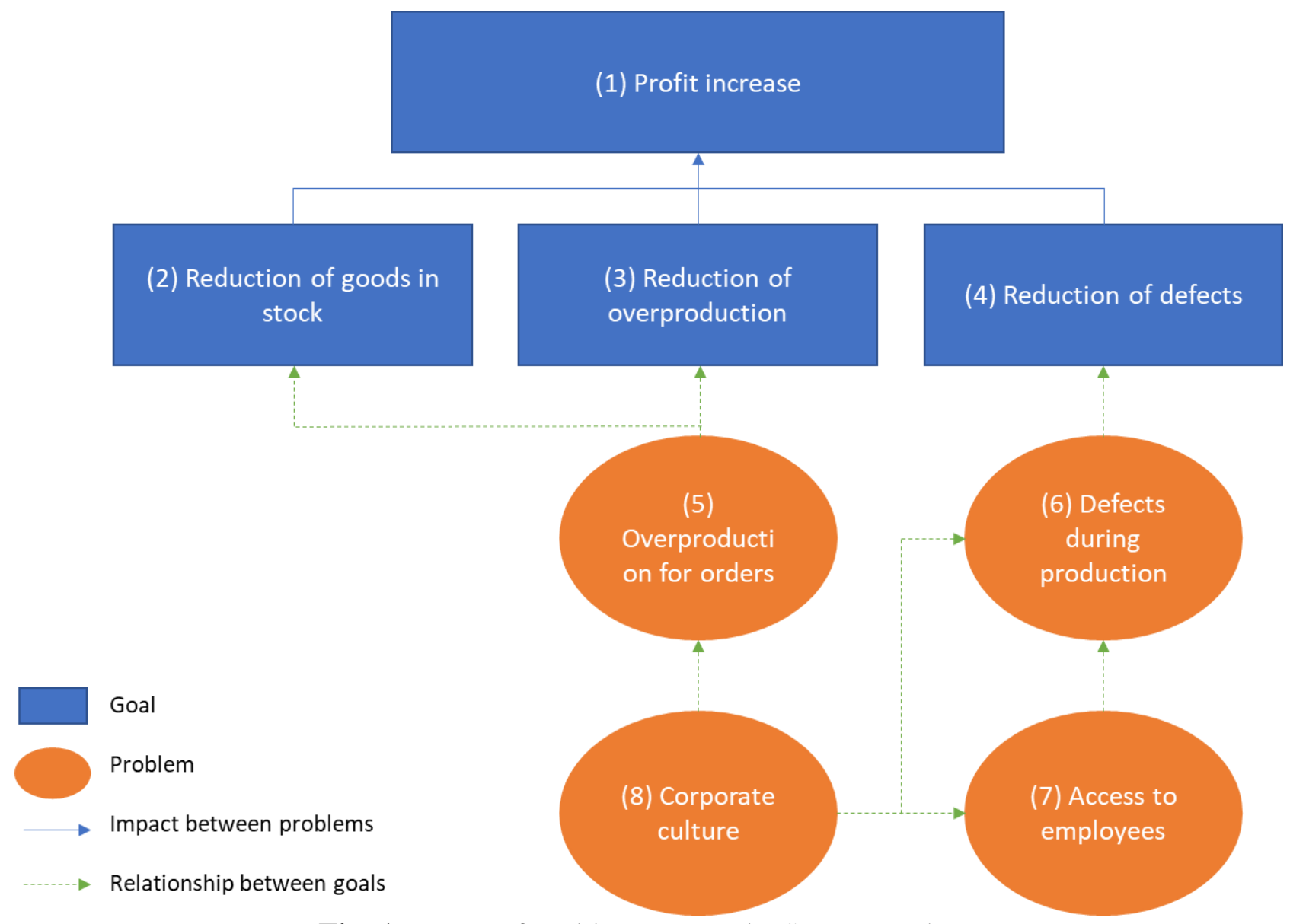

Fig. 1 Impact of problems on goals. Source: authors

The following problems are of concern in the observed situation:

(a) Overproduction for orders places an unnecessary burden on storage space, thereby creating undesirable costs. The reduction or complete elimination of this overproduction is a key factor in achieving the objectives of reducing goods in stock (2) and increasing profits (1).

(b) Production defects are an unnecessary waste of the company's resources. By eliminating this problem, the defect rate will drop accordingly, enabling the fulfilment of objectives (4) and (1).

(c) The attitude towards employees is a problem and affects product defects. This is related to the engagement of part-time workers who are not familiar with or improperly handle materials and goods. It is therefore important for the company to create better conditions for more experienced employees. Access to employees is therefore another key issue that hinders the achievement of objectives (4) and (1).

(d) Corporate culture influences a company's objectives and the achievement thereof. Setting the right corporate culture is key to increasing productivity and motivating employees to fulfil plans. 
To better obtain information about these individual problems, it is necessary to determine where, how and by whom such information should be collated. This is summarised in the table 1 below.

Table 1 Obtaining information. Source: authors

\begin{tabular}{|c|c|c|c|c|}
\hline & $\begin{array}{l}\text { Department } \\
\text { /place in } \\
\text { company }\end{array}$ & $\begin{array}{c}\text { Responsible person, } \\
\text { time spent }\end{array}$ & $\begin{array}{l}\text { Processing and } \\
\text { evaluation of } \\
\text { information }\end{array}$ & $\begin{array}{l}\text { Method of transmitting } \\
\text { information to } \\
\text { management }\end{array}$ \\
\hline $\begin{array}{l}\text { Number of } \\
\text { products with } \\
\text { defects }\end{array}$ & Manufacturing & $\begin{array}{ll} & \text { Employee of } \\
\text { controlling } \\
\text { department } \\
\text { - } \\
\text { Time for the } \\
\text { production process } \\
\text { - } \begin{array}{l}\text { Multiple } \\
\text { measurements }\end{array}\end{array}$ & $\begin{array}{ll}- & \text { Processing = } \\
\text { responsible person } \\
\text { - } & \text { Evaluation = head } \\
\text { of the relevant } \\
\text { department }\end{array}$ & $\begin{array}{ll}- & \text { Production report } \\
\text { - } & \text { After performing } \\
\text { multiple } \\
\text { measurements } \\
\text { - } & \text { Personal submission }\end{array}$ \\
\hline $\begin{array}{l}\text { Number of } \\
\text { ordered } \\
\text { products }\end{array}$ & Sales & $\begin{array}{ll} & \text { Sales worker } \\
\text { - } & \text { Time required to } \\
\text { receive and process } \\
\text { an order }\end{array}$ & $\begin{array}{ll}- & \text { Processing = } \\
\text { responsible person } \\
-\quad & \text { Evaluation = head } \\
\text { of the relevant } \\
\text { department }\end{array}$ & $\begin{array}{ll}- & \text { Production order / } \\
\text { order } \\
\text { - } & \text { Personal submission }\end{array}$ \\
\hline $\begin{array}{l}\text { Number of } \\
\text { products after } \\
\text { the } \\
\text { production } \\
\text { process }\end{array}$ & Manufacturing & 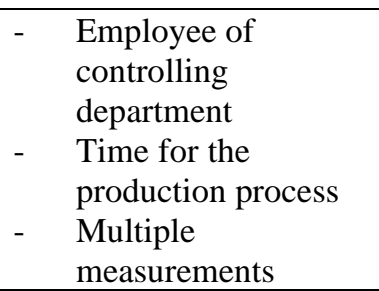 & $\begin{array}{ll} & \text { Processing = } \\
\text { responsible person } \\
\text { - } & \text { Evaluation = head } \\
\text { of the relevant } \\
\text { department }\end{array}$ & $\begin{array}{ll}- & \text { Production report } \\
- & \text { After performing } \\
\text { multiple } \\
\text { measurements } \\
\text { - } & \text { Personal submission }\end{array}$ \\
\hline $\begin{array}{l}\text { Number of } \\
\text { products in } \\
\text { stock }\end{array}$ & $\begin{array}{c}\text { Warehouses } \\
\text { (stock records) }\end{array}$ & $\begin{array}{ll}- & \text { Logistics and supply } \\
\text { staff } \\
\text { - } \quad \text { Can be done } \\
\text { immediately }\end{array}$ & $\begin{array}{ll}- & \text { Processing = } \\
\text { responsible person } \\
\text { - } & \text { Evaluation = head } \\
\text { of the relevant } \\
\text { department }\end{array}$ & $\begin{array}{ll}- & \text { Stock records } \\
- & \text { After performing the } \\
\text { relevant production } \\
\text { process } \\
\text { - } & \text { Personal submission }\end{array}$ \\
\hline $\begin{array}{l}\text { Employee } \\
\text { satisfaction }\end{array}$ & $\begin{array}{c}\text { Workplace } \\
\text { (employees) }\end{array}$ & $\begin{array}{ll}- & \text { Employee of HR } \\
\text { department } \\
\text { - } \quad \text { Time - } 3 \text { months }\end{array}$ & $\begin{array}{ll}- & \text { Processing = } \\
\text { responsible person } \\
\text { - } & \text { Evaluation = head } \\
\text { of the relevant } \\
\text { department }\end{array}$ & $\begin{array}{ll}- & \text { Analysis of results of } \\
\text { a questionnaire survey } \\
\text { / interviews } \\
\text { - } \quad \text { Personal submission }\end{array}$ \\
\hline $\begin{array}{l}\text { Number of } \\
\text { job } \\
\text { applications }\end{array}$ & $\begin{array}{c}\text { Human } \\
\text { Resources }\end{array}$ & $\begin{array}{ll} & \text { Employee of HR } \\
\text { department } \\
-\quad & \text { Duration of } \\
& \text { recruitment process }\end{array}$ & $\begin{array}{ll}\text { - } & \text { Processing = } \\
\text { responsible person } \\
\text { - } & \begin{array}{l}\text { Evaluation = head } \\
\text { of the relevant } \\
\text { department }\end{array}\end{array}$ & $\begin{array}{ll}\text { - } & \text { Statement on the } \\
\text { number of job seekers } \\
\text { - } & \text { Personal submission }\end{array}$ \\
\hline
\end{tabular}

An explanation of the above follows.

Information on the number of defective products should be obtained from the production process and their number directly recorded during this process. In ideal circumstances, the time for obtaining this information is equivalent to the production time, which includes the recording of defective products, which can then be expressed in terms of the additional costs to the company. 
Table 2 Obtaining information. Source: authors

\begin{tabular}{|l|l|l|l|l|l|l|l|}
\hline Date & $\begin{array}{c}\text { Time } \\
\text { interval }\end{array}$ & $\begin{array}{c}\text { Work } \\
\text { shift }\end{array}$ & Shift manager & $\begin{array}{c}\text { Line } \\
\text { number }\end{array}$ & $\begin{array}{c}\text { Number of } \\
\text { defective } \\
\text { products }\end{array}$ & Order number & Product type \\
\hline & & & & & & & \\
\hline & & & & & & & \\
\hline
\end{tabular}

Separate Excel forms, like the one above, be filled in for each production line. Every hour, the heads of the individual production lines should fill in the required data. Because the data is stored electronically, it would be available in real time for corporate controlling. Electronic data collection saves time with regards to data processing, unlike paper collection, see figure 2.

\begin{tabular}{|c|c|c|c|c|c|c|c|c|c|}
\hline 4 & A & B & C & D & E & $\mathrm{F}$ & G & $\mathrm{H}$ & I \\
\hline 1 & Date & Time interval & Work shift & $\begin{array}{c}\text { Change } \\
\text { manager }\end{array}$ & fine numbe & $\begin{array}{c}\text { Number of } \\
\text { discrepanc } \\
\text { ies }\end{array}$ & $\begin{array}{c}\text { Order } \\
\text { number }\end{array}$ & $\begin{array}{c}\text { Product } \\
\text { type }\end{array}$ & \\
\hline 2 & 20.11 .2018 & 09:00-10:00 & 1 & Honza & 101 & 1 & 188947 & $\mathrm{H} 125 \mathrm{C}$ & \\
\hline 3 & 20.11 .2018 & $10: 00-11: 00$ & 1 & Honza & 101 & 7 & 188947 & $\mathrm{H} 125 \mathrm{C}$ & \\
\hline 4 & 20.11 .2018 & $11: 00-12: 00$ & 2 & Jozo & 101 & 15 & 188948 & $\mathrm{G} 102 \mathrm{C}$ & \\
\hline 5 & 20.11 .2018 & $12: 00-13: 00$ & 2 & Jozo & 101 & 3 & 188948 & $\mathrm{G} 102 \mathrm{C}$ & \\
\hline \multicolumn{10}{|c|}{6} \\
\hline \multicolumn{10}{|l|}{7} \\
\hline \multicolumn{10}{|l|}{8} \\
\hline \multicolumn{10}{|l|}{9} \\
\hline \multicolumn{10}{|l|}{10} \\
\hline \multicolumn{10}{|l|}{11} \\
\hline \multicolumn{10}{|l|}{12} \\
\hline \multicolumn{10}{|c|}{13} \\
\hline \multicolumn{10}{|c|}{14} \\
\hline$\cdots$ & , & roduction line 1 & produc & ction line 2 & produ & uction line 3 & pro & ction lit & ) \\
\hline
\end{tabular}

Fig. 2 Sample of filled in Excel form. Source: authors

Multiple parameters are required to generate objective and correct information. The result is the average number of defective products per production process, alternatively the number of identically produced pieces and, at the same time, the identification of processes in which the highest rate of overproduction occurs. The information should be ascertained and processed by an authorised employee of the controlling department in the company. The information obtained can then be presented to the company's management in the form of a production report.

Information on the number of ordered products can be found in the order, after the receipt and processing thereof. An authorised employee of the company's sales department should be responsible for obtaining and processing this information. The form in which the ascertained information is subsequently presented to the company's management could be the order itself or the production order, either of which will contain the number of ordered pieces. 
Another important piece of information is the number of products after the production process. This can be used to determine the level of overproduction, which is currently a large problem. The information should be obtained during the production process, with the thorough registration of the number of finished products. If the aforementioned conditions are met, the time for obtaining the information is equivalent to the duration of the production process. The responsible person should be an authorised employee of the controlling department, who also processes the information. The form of information transfer could be a production report.

At present, the company has a large number of products lying in warehouses, which is another important piece of information for the company's management. This information can be ascertained through stock records, with the source of information being the warehouses themselves, which are currently overstocked. Thorough records of stored products provide information to management on the amount of overproduction and, at the same time, reduce the time needed to obtain this information. The person responsible for obtaining and processing this information should be an employee of the logistics and supply department.

Information on employee satisfaction can be found directly in the workplaces of individual employees. In this case, for example, in production. It is the task of the human resources department to take care of employees, and therefore to also determine their satisfaction. A questionnaire survey is the best way to achieve this. The process should take approximately 3 months; 2 months for the preparation, correction and processing of the questionnaire and 1 month for employees to complete it. The form in which this information should be submitted is a report containing a comprehensive analysis of the processed results.

Information on the number of job applications can be obtained from the company's human resources department (Table 2). The time for obtaining this information is the duration of the recruitment process during which individuals can apply for employment. Information on the number of job applications could be submitted to the company's management in the form of a statement on the number of job seekers, based on real interest in a job in the company.

The information obtained should be evaluated by the heads of the relevant departments, who subsequently pass this on to the company's management in person.

\section{Logistics in Production Using UAV Devices}

An example of this issue in practice is that of the automobile industry. A large number of different components, semi-finished products and energy are consumed in the production of a vehicle. For this reason, it is necessary to have a logistics network that is capable of replenishing components exactly on time, so no shortages occur during assembly operations. If this were to happen, the entire production line would need to be shut down until the components became available again. One option 
to address the problem is to apply modern technologies, such as vehicles and devices operated, respectively driven and loaded by people. However, this method poses several risks in terms of collisions, injuries, damage to devices and/or components.

An innovative alternative is for car manufacturers to start using unmanned aerial vehicles (UAV) for internal logistics, thereby replacing designated ground routes with air corridors. This would ensure more efficient logistics in production and present new options for managing the JIT system. Delays or delays in delivery would also be avoided because such devices would be controlled by a central system and the shortest route could always be chosen.

In order to be able to implement this innovation, it is necessary to develop a system that guarantees the preparation and dispensation of components in/from the warehouse, as well as the movement of the UAV devices themselves. This includes connection of the assembly points to the system in order to be able to check which components need to be replenished, as well as modification of the racks and holders for these components so that they are accessible with UAV devices. Such an innovation would also create new jobs linked to the implementation, operation and maintenance of the system.

\section{Discussion}

Through the case study, the business elements that support, as well as undermine, the goals of the company in terms of costs of production were determined. In response to the main problems, suggestions and recommendations were put forward to obtain relevant information for future decision-making on these problems. A number of the identified problems, the most fundamental of which is the rate of defective products, pose a serious threat to the company's survival if corrective measures are not taken.

Obsolete production lines were identified as the main cause of the defective products. The gradual replacement of production lines according to available corporate resources was therefore suggested. The proposal is considered realistic and achieveable, based on the reinvestment of profits and not loans. The objective to reduce, preferably eliminate, the daily cost of defective products by $10 \%$ in the following marketing year is urgent. The suggested method for obtaining information about the problems will also provide insights into how to proceed in the future with regards to the fulfilment of controlling activities within logistics processes in the company.

Controlling as a future-oriented system of modern business management, with an emphasis on the correct creation and quantification of business objectives, will serve to ensure the long-term survival of the company. The reason for this is that a very significant characteristic of controlling is, in contrast to traditional tools of business analysis, its orientation towards the future. 
However, there are many reasons why controlling does not work (unaddressed and incomplete reporting; it is understood only as an economic tool; there is no controlling information system; etc.). The success of controlling, or lack thereof, will depend on whether the company's managers are willing to accept change and better manage logistics operations within the company. Through controlling, it is also possible to increase the responsibility of employees with regards to the fulfilment of their tasks and their contribution to the streamlining of logistics processes. Businesses without controlling, unwittingly waste a lot of money.

\section{Acknowledgments}

This publication was made possible with the support of the Operational Program Integrated Infrastructure 2014 - 2020 of the project: Intelligent Operating and Processing Systems for UAVs, code ITMS 313011V422, co-financed by the European Regional Development Fund.

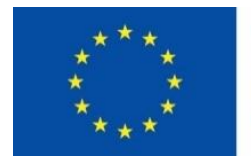

\section{EUROPEAN UNION}

European Regional Development Fund

OP Integrated Infrastructure 2014 - 2020

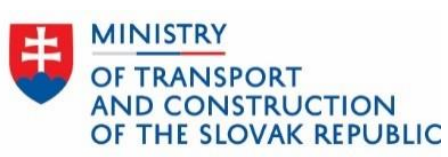

\section{References}

[1] Chapman, C. (2005). Controlling Strategy: Management, Accounting, and Performance Measurement. Oxford, England: Oxford University Press; Illustrated edition. ISBN: 9780199283231.

[2] Ferenc, P., Varmus, M. \& Vodák, J. (2017). Stakeholders in the Various Field and Relations between Them. Procedia Engineering Vol 192, 166-170. DOI: 10.1016/j.proeng.2017.06.029.

[3] Eschenbach, R. (2000). Controlling. Praha, Czech Republic: Aspi Publishing. ISBN 8085963-86-8.

[4] Horváthová, J. \& Gallo, P. (2003). Controlling and efective management. Prešov, Slovakia: Grafotlač. ISBN 978-80-8165-129-8.

[5] Baran, D. (2015). Controlling. Bratislava, Slovakia: STU. ISBN 978-80-227-4332-7.

[6] Sedliacikova, M., Vacek, V. \& Sopkovac, E. (2015). How Slovak Small and Medium Enterprises Perceive in Financial Controlling In Procedia Economics and Finance, Vol. 26, 82-85. DOI: 10.1016/s2212-5671(15)00842-4.

[7] Implementing Control Measures (2019). Retrieved October 21, 2020, from https://www.signavio.com/business-scenarios/implementing-control-measures//

[8] Štreit, V. (2007). Modern controlling. Retrieved October 25, 2020, from https://modernirizeni.ihned.cz/c1-22611300-moderni-controlling

[9] Sedliačiková, M., Šatanová, A. \& Foltínová, A. (2012). Finance Controling in Theory and Praxis of Small Companies. Economical journal, Vol. 60 (9), 949-966. ISSN 0013-303. 
[10] Varmus, M., Kubina, M., Koman, G. \& Ferenc, P. (2010). Ensuring the Long-Term Sustainability Cooperation with Stakeholders of Sports Organizations in Slovakia. Sustainability 10(6), 1833, 371-380. ISSN: 2071-1050.

[11] Ližbetin, J., Bartuška, L. \& Rakhmangulov, A. (2016). A Case Study of the Evaluation of the Quality of Connections on the Railway Transport Network in the South Bohemian Region In Transportation Research Procedia. Vol. 53, Amsterdam, Netherlands: Elsevier B.V., 2021. 66-71. ISSN 2352-1457.

[12] Klieštik, T., Slamakhina, E. \& Zhuraleva, N. (2021) Methodology of building relationships with customers in the area of transport services In The Archives of Automotive Engineering, 93(3), 59-65. DOI: 10.14669/AM.VOL93.ART4.

[13] Chmelár, M. (2020). Reporting In Power BI, PowerPivot DAX. ISBN: 978-80-9773078-0-6.

[14] Jankal, R. \& Jankalova, M. (2016). The application of The EFQM Excellence Model by the evaluation of Corporate Social Responsibility activities of companies. Procedia Economics and Finance 39, 660-667. DOI: 10.1016/S2212-5671(16)30313-6.

[15] Montgomery, D.C. \& Woodall, W.H. (1997). A discussion on statistically-based process monitoring and control. Journal of quality technology 29(2), 157-162 DOI: 10.1080/00224065.1997.11979738.

[16] Airikka, P. (2004). Advanced control methods for industrial process control. IEE Computing and Control Engineering 15(3), 18-23. ISSN: 0956-3385.

[17] Nekvapil, T. (2012). Five obstacles on the way to effective controlling In IEE Computing and Control Engineering 15(3), 18-23. ISSN: 0956-3385.

[18] Waniczek, M. (2013). Measuring Performance and Increasing Performance in Controlling $\begin{array}{lllll}\text { Processes. } & \text { Retrieved } & \text { October } & 20, & 2020,\end{array}$ https://cafin.cz/wpcontent/uploads/2017/05/CAFINews_2_vydani_listovaci_PDF.pdf

[19] Zrakova, D., Kubina, M. \& Koman, G. (2017). Influence of Information-Communication System to Reputation Management of a Company. Procedia Engineering 192, 1000-1005. DOI: $10.1016 /$ j.proeng.2017.06.172.

[20] Hittmar, S., Varmus, M. \& Lendel, V. (2015). Proposal of Evaluation System for Successful Application of Innovation Strategy through a Set of Indicators. Procedia Economics and Finance 26, 17-22. DOI:10.1016/S2212-5671(15)00796-0.

[21] Dorcak, P., Markovic, P. \& Pollak, F. (2017). Multifactor Analysis of Online Reputation as a Tool for Enhancing Competitiveness of Subjects from Automotive Industry. Economical Journal, 65(2), 173-186. ISSN 0013-3035. 